La historia transnacional de las derechas argentinas en el siglo XX: ¿qué sabemos y qué podríamos saber?

Ernesto Bohoslavsky

páginas / año 10 - n² 24 Septiembre-Diciembre / ISSN 1851-992X/ pp.10-33/

2018

http://revistapaginas.unr.edu.ar/index.php/RevPaginas

\title{
La historia transnacional de las derechas argentinas en el siglo XX: ¿qué sabemos y qué podríamos saber? *
}

\author{
The Transnational History of Argentine Right-Wings in the 20th \\ century: what do we know and what could we know?
}

\author{
Ernesto Bohoslavsky \\ Universidad Nacional de General Sarmiento, \\ Consejo Nacional de Investigaciones Científicas y Técnicas, Argentina \\ ebohos@gmail.com
}

\begin{abstract}
Resumen
En este artículo se exploran las principales vías por las que ha transitado el estudio transnacional de diversas ideologías y actores de derecha de la Argentina del siglo XX. En particular, son cuatro las áreas de estudio por lo que se interesa este texto: a) la consagrada a los actores militares desde finales del siglo XIX bajo el influjo del prusianismo hasta el impacto de la Escuela Francesa contrarrevolucionaria y de la Doctrina de la Seguridad Nacional, b) la relativa a la Iglesia católica, sus textos y sus hombres y organizaciones paraeclesiásticas como la Sociedad para la Defensa de la Tradición, Familia y Propiedad; c) la dedicada a políticos y publicaciones conservadoras, nacionalistas y anticomunistas, d) finalmente, la que atiende a los expertos y las redes de académicos vinculados a las derechas desde finales del siglo XIX y hasta los actuales think tanks. En la última sección se ofrecen algunas ideas para una agenda de investigación sobre historia transnacional de las derechas argentinas.
\end{abstract}

Palabras clave

Historia transnacional; Historiografía; Derechas; Argentina; Metodología

\section{Abstract}

This article explores the most important approaches to the transnational history of Rightwing ideologies and actors in Argentina in the 20th century. This text concentrates in four areas: a) the history of the Armed Forces which were under influence of many foreign

\footnotetext{
* Versiones previas de este texto fueron presentadas en la Jornada "Las derechas argentinas en el siglo XX" (Tandil, 11 y 12 de octubre de 2018) y la Jornada de estudios "Hacia una historia transnacional de las derechas latinoamericanas, siglo XX" (Santiago de Chile, 23 de octubre de 2018). Agradezco a los y las colegas que participaron de estos eventos por la posibilidad de discutir y afinar mejor estas ideas. Ana Clarisa Agüero hizo una lectura tan precisa y generosa de estas páginas que me deja gravemente endeudado con ella.

Esta obra está sujeta a la Licencia Reconocimiento-NoComercial-CompartirIgual 4.0 Internacional de Creative Commons. http://creativecommons.org/licenses/by-nc-sa/4.0/

(c) EY-NC-SA
} 


\section{Ernesto Bohoslavsky}

military doctrines since the end of the $19^{\text {th }}$ century like Prussianism, French counterrevolutionary Theory and US' National Security Doctrine; b) the study of the Catholic Church, the clergy and its documents and its parallel organizations such as the Sociedad para la Defensa de la Tradición, Familia y Propiedad; c) conservative, nationalist and anticommunist politicians and journals; d) the historical and sociological approach to expertise and scholar networks linked to right-wing ideas, from the late $19^{\text {th }}$ century until current think tanks. The final section offers some suggestions to improve the agenda of the transnational history of the Argentina right-wings.

\section{Keywords}

Transnational History; Historiography; Right-wings; Argentina; Methodology

En este texto ofrezco un estado de la cuestión inicial sobre la historiografía dedicada a la circulación transnacional de actores de derecha en la Argentina entre finales del siglo XIX y la década de 1980. No escapa al autor que la definición de "derechas" es esencialmente problemática y que la mera presentación de algunos de los debates sobre el particular insumiría un espacio del que aquí se carece. En todo caso, baste indicar que propongo caracterizar a dos conjuntos de actores de derecha: por un lado tenemos una derecha "social" que abarca a los que detentan las diversas formas de poder económico (capitalistas), religioso (sacerdotes e iglesias) y militar (integrantes de las Fuerzas Armadas). ${ }^{1}$ Esa "derecha social" está ligada a actores muy fuertemente institucionalizados y formalmente no políticos, pero que actúan de facto como defensores del status quo (lo cual no quiere decir que todos los integrantes de la Iglesia o de las Fuerzas Armadas fueran de derecha). Por el otro lado, unas derechas "políticas", compuestas por los dirigentes políticos, los votantes, los ideólogos, los expertos, los militantes y las organizaciones explícitamente afiliadas a ideas conservadoras del orden social. Se trata en estos casos de actores explícita o formalmente políticos, que intervienen en la búsqueda del poder político o en las tareas intelectuales de legitimación de la dominación política.

La primera sección de este artículo se concentra en el análisis de la bibliografía sobre actores de la "derecha social". Se revisan algunos de los estudios sobre a) las Fuerzas Armadas argentinas y la llegada y diseminación de doctrinas castrenses provenientes de regiones metropolitanas (primero Prusia, luego Francia y finalmente los Estados Unidos de América), b) la Iglesia católica y organizaciones como la Sociedad para la Defensa de la Tradición, la Familia y la Propiedad (tfp), que mostraron desde sus inicios una fuerte actividad transnacional. En la segunda sección se presentan varios estudios que se han dedicado a analizar la circulación de ideologías de extrema derecha entre Argentina y países americanos y europeos y las redes de expertos y de think tanks. Finalmente, en las conclusiones se presentan algunas ideas acerca de los rasgos y los límites que han tenido los acercamientos a

\footnotetext{
${ }^{1}$ Barry Cannon, The Right in Latin America: Elite Power, Hegemony and the Struggle for the State, Londres, Routledge, 2016.
} 


\section{La historia transnacional de las derechas argentinas en el siglo XX: ¿qué sabemos y qué podríamos saber?}

una historia transnacional de las derechas realizados en Argentina, así como una posible agenda de investigación a futuro sobre estas cuestiones.

Dos observaciones se pueden desprender de este estado de la cuestión sobre la vida transnacional de las derechas argentinas: en primer lugar que los historiadores hoy en lugar de atender a la llegada de doctrinas del Atlántico norte que se presumen sistemáticas y completas, se interesan por las apropiaciones selectivas, los usos y las reinvenciones parciales de un cierto conjunto ideológico por parte de obispos, políticos y generales; en segundo lugar, que los historiadores de las derechas hoy tienden a percibir a las instituciones -sean éstas la Iglesia, los partidos o los grupos de presión- como arenas de disputa en sí mismas más que como vehículos de transmisión de arriba hacia abajo de nociones y diagnósticos generados por sus cúpulas.

\section{Las derechas "sociales": militares y sacerdotes}

Los primeros esfuerzos sistemáticos por comprender histórica y políticamente al Ejército fueron realizados por investigadores extranjeros en los años sesenta y setenta. Robert Potash en The Army and Politics in Argentina, 1928-1945² de 1969 y Alain Rouquié en Pouvoir militaire et société politique en République Argentine ${ }^{3}$ de 1978 desplegaron un trabajo de investigación de largo alcance que permitió obtener un panorama completo de diversos aspectos de la corporación castrense a lo largo del siglo XX. Así, fueron relevados temas como las líneas ideológicas internas, los vínculos con políticos, los procesos de formación profesional e ideológica así como la constitución de los patrones de intervención en la vida política del país. Aunque de forma desigual, en ambos libros podemos encontrar un anhelo por reconstruir históricamente -y a su vez por condenar- el proceso por el cual las Fuerzas Armadas consiguieron devenir actores semi-legítimos del juego político desde la década de 1930. Sendos autores escribieron y publicaron cuando ese patrón estaba lejos de estar agotado y en algún sentido intentaban comprender el presente que los argentinos estaban viviendo.

Quizá por provenir del exterior, tanto Rouquié como Potash mostraron interés por conocer los procesos de circulación de ideologías desde los países centrales hacia el Ejército argentino. En ambos casos ese interés se vio facilitado por la posibilidad de acceder a una variedad de documentos y de entrevistas formales e informales en sus países de origen. De allí la relevancia dada a la pregunta por los mecanismos de llegada, difusión y aceptación de los principios provenientes de la teoría francesa de la guerra contra-revolucionaria o de la doctrina de la seguridad nacional emitida desde The School of the Americas en Panamà.

\footnotetext{
2 Robert Potash. The Army and Politics in Argentina, 1928-1945: Yrigoyen to Perón. Stanford, Stanford University Press, 1969.

${ }^{3}$ Alain Rouquié. Pouvoir Militaire et Société Politique en République Argentine. París, Presses de la Fondation Nationale des Sciences Politiques, 1978.
} 


\section{Ernesto Bohoslavsky}

Otra generación más joven de investigaciones se puede identificar en los últimos quince años gracias a algunos rasgos propios. Autores como Daniel Mazzei ${ }^{4}$ o Mario Ranaletti ${ }^{5}$ han contribuido a tener una idea más ajustada de la vida ideológica dentro de las Fuerzas Armadas. Sus acercamientos carecen de la ambición explicativa de Rouquié y de Potash, que abarcaba décadas de vida dentro de los cuarteles. Los autores más recientes han abandonado la ambición explicativa de larga duración tendiente a identificar los nudos centrales de la vida argentina en el siglo XX y se han concentrado en producir investigaciones igualmente sólidas, pero con un recorte cronológico y temático más acotado. Esta historiografía también se ha preocupado por los recorridos de formación de diversos oficiales, especialmente durante los años sesenta y setenta del siglo XX. Tenemos estudios serios sobre las enseñanzas en las aulas, las lecturas a las que estaban expuestos y los docentes que escucharon oficiales y suboficiales. En particular, el trabajo de Esteban Pontoriero ${ }^{6}$ nos permite saber cuáles fueron las variaciones doctrinarias y teóricas que vivió el Ejército Argentino desde los años de Frondizi, así como el impacto proveniente de las interacciones con Fuerzas Armadas igualmente involucradas en una agenda hemisférica anticomunista. De manera pionera Ariel Armony, y luego Julieta Rostica han realizado una serie de aportes muy importantes en el campo del estudio de las relaciones clandestinas entre las Fuerzas Armadas argentinas y las centroamericanas en las décadas de 1970 y 19807. En el marco de la retirada del apoyo estadounidense a las dictaduras de la región con el gobierno de Jimmy Carter, estos regímenes militares buscaron solidaridades mutuas $y$ formas de asesoramiento en materia de lucha antisubversiva.

Probablemente la más impactante de las investigaciones realizadas en los últimos años provino de Marie-Monique Robin y su película de 2003 Escadrons de la mort, l'école française a la que le siguió el libro del mismo nombre. ${ }^{8}$ Tanto el documental como el libro ilustran con numerosos testimonios las conexiones de los servicios secretos franceses con las dictaduras argentina y chilena en los años sesenta y

\footnotetext{
4 Daniel Mazzei, "La misión militar francesa en la Escuela Superior de Guerra y los orígenes de la guerra sucia", Revista de Ciencias Sociales, n. 13, 2002, pp. 105-137; Bajo el poder de la caballería: El ejército argentino (1962-1973). Buenos Aires, Eudeba, 2012.

${ }_{5}^{5}$ Mario Ranaletti. "Aux origines du terrorisme d'État en Argentine", Vingtième siècle. Revue d'histoire, n. 1,2010, pp. 45-56; "Una aproximación a los fundamentos del terrorismo de estado en la Argentina: la recepción de la noción de" guerra revolucionaria" en el ámbito castrense local (1954-1962)", Anuario del Centro de Estudios Históricos "Prof. Carlos Segreti", v. 11, n. 11, 2011, pp. 261-278

6 Esteban Pontoriero. "Pensamiento militar y legislación de defensa en la Argentina: la caracterización de la amenaza a la seguridad interna. ¿Continuidad o ruptura? (1963-1970)", Contemporánea, año 3, vol. 3, 2012, pp. 149-166; "Estado de excepción y contrainsurgencia: el plan CONINTES y la militarización de la seguridad interna en la Argentina (1958-1962), Contenciosa, año III, $n^{\circ} 4,2015$, pp. 1-16; "La seguridad interna como 'teatro de guerra': estado de excepción y contrainsurgencia en Argentina (1955-1976)", Tesis de Doctorado, Instituto de Altos Estudios Sociales, Universidad Nacional de San Martín, Buenos Aires, 2017.

${ }^{7}$ Ariel Armony, La Argentina, los Estados Unidos y la cruzada anticomunista en América Central, 19771984, Bernal, Universidad Nacional de Quilmes, 1999. Julieta Rostica. "Una agenda de investigación pendiente: la política exterior de la dictadura militar argentina hacia Guatemala (1976-1983)", Asociación para el Fomento de los Estudios Históricos en Centroamérica, 2013.

${ }^{8}$ Marie-Monique Robin. Escadrons de la mort, l'école française. París, La Découverte, 2004.
} 


\section{La historia transnacional de las derechas argentinas en el siglo XX: ¿qué sabemos y qué podríamos saber?}

setenta. Esas vinculaciones permitieron la transferencia de técnicas de contrainsurgencia urbana oportunamente exploradas en la guerra en Argelia (1954-1962): esas tecnologías para la obtención de información y para la eliminación de las amenazas ideológicas le dieron operatividad al Plan Cóndor. Una figura como Roger Trinquier, teórico de la actividad contra-subversiva e integrante de Cité Catholique, reclutó -según Robin- a viejos miembros de la Organisation de l'Armée Secrète para actividades de terrorismo y actuó como docente en la Escuela Superior de Mecánica de la Armada, uno de los más importantes centros clandestinos de detención durante la última dictadura. El trabajo de Robin contribuyó a difundir algunos de las formas desconocidas de colaboración clandestina entre Francia y las dictaduras, pero sus despliegues espectacularizantes y su deseo de desenmascarar las complicidades francesas -e incluso de judicializarlas- contribuyó menos a una comprensión más profunda e historiográfica de esos procesos y sus lógicas.

Como es sabido, la Iglesia es una institución per se transnacional. Sin embargo, no siempre se han utilizado metodologías que permitan percibir esa dimensión de las actividades, identidades y discursos católicos ni se ha concebido problemáticamente a la institución como una entidad universal. En particular, los investigadores identificados con la fe católica tendieron a naturalizar o a no percibir esa dimensión transnacional del mundo católico: así, que Jacques Maritain fuera leído muy lejos de Francia, que los Legionarios de Cristo tuvieran sedes de sus colegios en distintas partes de América del sur o que la teología de la liberación del sacerdote peruano Gustavo Gutiérrez contara con lectores en el nordeste de Brasil o en la villa de Retiro en Buenos Aires era un dato perfectamente previsible dado el carácter universal o potencialmente universal de la pertenencia católica. Los últimos veinte años nos han permitido hacernos de lecturas bastante más complejas sobre estas cuestiones. Ello ha sido posible por el impactante crecimiento del campo multidisciplinario de estudios sobre los fenómenos religiosos y la vida eclesiástica, un campo cuya envergadura y producción son imposibles de reseñar aquí, y que se expresa en la vitalidad de publicaciones como Sociedad y Religión (editada desde 1985 y auspiciada por la Asociación de Cientistas Sociales de la Religión del Mercosur ${ }^{9}$ ) y las periódicas reuniones del Grupo de Trabajo de Religión y Sociedad en la Argentina Contemporánea (RELIG-AR) con sede en las Universidades de Buenos Aires y del Centro de la Provincia de Buenos Aires. ${ }^{10}$

El afianzamiento de los ámbitos académicos dedicados al estudio de los fenómenos religiosos ha contribuido enormemente a que hoy tengamos un mapa más completo

\footnotetext{
9 El archivo de la revista está disponible en http://www.ceilconicet.gov.ar/ojs/index.php/sociedadyreligion/issue/archive Con menor recorrido pero igual especialidad temática tenemos a Itinerantes. Revista de Historia y religión, disponible en: http://itinerantes.unsta.edu.ar/ojs/index.php/Itinerantes/index

${ }^{10}$ El sitio web del Grupo es http://religargrupo.blogspot.com/
} 


\section{Ernesto Bohoslavsky}

sobre el catolicismo y la Iglesia argentina. Hace dos décadas se pensaba que la Iglesia argentina era, tal como insistió Loris Zanatta, una de las más completamente romanizadas a finales del siglo XIX. ${ }^{11}$ Ello habría implicado una ideología monolítica y una fuerte dependencia de los lineamientos teológicos y políticos del Vaticano frente a aquellos surgidos localmente. Esa subordinación se habría expresado en un mayor integrismo católico ${ }^{12}$ en comparación con otros países de la región como Chile -y desde ya Uruguay-. Hoy nuestra percepción de la Iglesia y de los católicos en Argentina es en buen a medida más compleja. Ello se advierte en el peso que se le reconoce a las identidades católicas que no eran integristas (liberales, antifascistas, conservadoras, etc.). El análisis de las "multitudes católicas", de la "política de masas" del catolicismo ha permitido saber cuán internacionalizadas estaban ciertas agendas y ciertos repertorios políticos para los sacerdotes y el laicado, pero también que la ciudadela católica no era en absoluto monolítica sino polifónica. ${ }^{13}$ Los acercamientos de historia trasnacional nos dejan ver el nivel de seguidismo de las decisiones vaticanas de la curia argentina de la Acción Católica desde los años veinte, pero también advierten sobre los niveles de autonomía y las discusiones internas. ${ }^{14}$ En particular, contamos con conocimientos más sólidos sobre las redes de catolicismo que se desplegaron a nivel internacional desde fines del siglo XIX. El estudio de revistas católicas, sobre todo de Criterio, ha permitido reconstruir algunos de los debates internacionales al interior del catolicismo. ${ }^{15}$ Algunos de esos debates mostraron tener una extensión que era más panamericana que hispanoamericana según ha mostrado Álvarez Satizábal. ${ }^{16}$ Sabemos algo sobre las actividades del padre Zacarías de Vizcarra en la promoción del catolicismo hispanófilo en Argentina a inicios del siglo XX, mientras que Miranda Lida ha mostrado el peso del catolicismo francés. ${ }^{17}$ En particular, en los últimos años se produjeron varios avances en la reconstrucción de las redes internacionales de las

\footnotetext{
${ }^{11}$ Loris Zanatta. Del Estado liberal a la nación católica. Iglesia y Ejército en los orígenes del peronismo. Buenos Aires, Universidad Nacional de Quilmes, 1996

${ }^{12}$ Fortunato Mallimaci. El catolicismo integral en la Argentina, 1930-1946. Buenos Aires, Fundación Simón Rodriguez y Biblos, 1988.

${ }^{13}$ Diego Mauro "Multitudes y movilizaciones católicas en la Argentina de entreguerras. Cuestiones metodológicas e historiográficas" en PolHis, № 8, 2011, pp. 90-96. Diego Mauro y Miranda Lida (coordinadores). Catolicismo y sociedad de masas en Argentina: 1900-1950. Rosario, Prohistoria, 2009.

${ }^{14}$ Jessica Blanco, "Las distintas juventudes de la iglesia en Argentina a mediados del siglo XX. Los casos de la Juventud de Acción Católica y la Juventud Obrera Católica", Letras Históricas, 4, 2011 pp. 139-160; Jessica Blanco, Modernidad conservadora y cultura política: la Acción Católica Argentina (1931-1941), Córdoba, Universidad Nacional de Córdoba, 2008.

15 Martín Vicente, "La cuestión del liberalismo en Orden Cristiano: entre las posiciones antifascistas y la problemática identitaria (1941-1948)", Pasado Abierto, v. 1, n. 2, 2015

16 Gineth Álvarez Satizábal (2015). "Ideas macro, acciones micro. Actores y redes del catolicismo integral en la educación de Argentina y Colombia (1930 y 1940)", tesis de Maestría, Universidad Nacional de San Martín.

${ }^{17}$ Miranda Lida, "Trazos francófilos en la cultura católica argentina de entreguerras", Boletín PolHis, v. 7 2014, p. 246-251. "De Manuel Gálvez a Jacques Maritain. Hispanofilia y francofilia en el catolicismo argentino de la primera mitad del siglo XX", Itinerantes. Revista de Historia y Religión, v.. 7, 2017, pp. 61-81.
} 


\section{La historia transnacional de las derechas argentinas en el siglo $\mathrm{XX}$ : ¿qué sabemos y qué podríamos saber?}

organizaciones católicas anti-conciliares. Elena Scirica ${ }^{18}$ estudió a revistas como Verbo y a organizaciones como Ciudad Católica mientras que Stephan Ruderer ${ }^{19}$ y Giselle Zanotto ${ }^{20}$ han reconstruido la creación de filiales de la tfp en Argentina y en Chile en las décadas de 1970 y 1980. Patricia Orbe ${ }^{21}$ y Facundo Cersósimo ${ }^{22}$ han estudiado los procesos de constitución de redes de católicos anti-conciliares y sedevacantistas, algunos de los cuales se comprometieron con la organización de la visita de monseñor Lefebvre al país en 1977. Esta serie de trabajos nos han permitido contar hoy en día con una visión más aguda y más fina de las redes internacionales- disímiles, competidas, enfrentadas y sólo a veces cooperativas- de las que participaban sacerdotes, laicos, periódicos y organizaciones. Ese panorama parece desdecir aquellas interpretaciones primigenias que intentaban ofrecer una imagen más sólida e homogénea de la vinculación entre la Iglesia argentina y las decisiones vaticanas.

\section{Las derechas políticas: del estudio de las influencias a las apropiaciones selectivas}

Muchos de los trabajos iniciales sobre las corrientes y figuras que podríamos conceptualizar como de derechas políticas argentinas identificaron las conexiones ideológicas existentes entre los doctrinarios europeos y sus pares rioplatenses: así, los textos de Zuleta Álvarez ${ }^{23}$, Barbero y Devoto ${ }^{24}$, Buchrucker ${ }^{25}$ y David Rock ${ }^{26}$ daban cuenta de las influencias de diversos autores y escuelas sobre actores argentinos. El tradicionalismo español de Menéndez Pelayo, el pensamiento reaccionario y de los anti-dreyfusards de la Tercera República francesa influyeron

\footnotetext{
18 Elena Scirica. "Visión religiosa y acción política. El caso de Ciudad Católica - Verbo en la Argentina de los años sesenta". PROHAL Monográfico, n. 2, 2010, pp. 26- 56. "Educación y guerra contrarevolucionaria. Una propuesta de Ciudad Católica-Verbo", Clio \& Asociados. La historia enseñada, n. 11, 2007, 119-140.

${ }^{19}$ Stephan Ruderer. "Cruzada contra el comunismo. Tradición, Familia y Propiedad (TFP) en Chile y Argentina”, Sociedad y Religión, v. XXII, n. 38, 2012.

${ }^{20}$ Gizele Zanotto. "A atuação do movimento católico Tradição, Família e Propriedade (TFP) no cenário político-cultural argentino (1967-1983)”, Revista Brasileira de História das Religiões, v. 20, 2014, p. 233-260; "A Associação Tradição, Família e Propriedade no Brasil e sua expansão para a Argentina", en Cândido Moreira Rodrigues, Gizele Zanotto y Rodrigo Coppe Caldeira (organizadores). Manifestações do Pensamento católico na América do Sul. São Paulo, Fonte Editorial, 2015, pp. 207-230.

21 Patricia Orbe. "Le nationalisme argentin et les débats sur les droites dans le Cône Sud de l'Amérique Latine de la seconde moitié du XXème siècle: progrès et défis dans le champ de la recherche historiographique", Cahier d'histoire immédiate, n. 46, 2014, pp. 51-65.

22 Facundo Cersósimo. "El Proceso fue liberal" Los tradicionalistas católicos argentinos y el Proceso de Reorganización Nacional (1976-1983)”, tesis del Doctorado en historia de la Facultad de Filosofía y Letras de la Universidad de Buenos Aires, 2015.

23 Enrique Zuleta Álvarez. El nacionalismo argentino. Buenos Aires, La Bastilla, 1975.

24 Barbero, María Inés y Devoto, Fernando. Los nacionalistas (1910-1932). Buenos Aires, Centro Editorial de América latina, 1983.

25 Christian Buchrucker. Nacionalismo y peronismo. La Argentina en la crisis ideológica mundial. Buenos Aires, Sudamericana, 1987.

${ }^{26}$ David Rock, La Argentina autoritaria. Los nacionalistas, su historia y su influencia en la vida pública. Buenos Aires, Ariel, 1993
} 


\section{Ernesto Bohoslavsky}

sobre las lecturas decadentistas argentinas de inicios del siglo XX, la Action Francaise impactó sobre los jóvenes que publicaban La Nueva República (1927-1931), el falangismo informó ideológicamente a la Alianza Juvenil Nacionalista (1937-1943) y luego a Tacuara (1958-1964). A su vez, estos libros nos permitían saber cuáles habían sido los impactos locales de los fenómenos políticos y militares ocurridos en Europa: Guerra civil española, ascenso del fascismo, segunda guerra mundial, etc. Sin menospreciar nada de los aportes contenidos en los libros antes mencionados, sólo me limito a señalar que en ellos hay más interés por percibir el peso de las doctrinas importadas que por conocer los mecanismos por los cuales esas doctrinas habían llegado, quiénes las habían importado inicialmente y con qué propósitos lo habían hecho. Textos como los de Buchrucker, Barbero y Devoto prácticamente dieron bautismo a los estudios sobre las derechas y lo hicieron sirviéndose de las preguntas que en los años ochenta orientaban el análisis histórico de las corrientes ideológicas.

Ese panorama cambió enormemente en lo que va de este siglo. En los últimos quince años hemos visto el despliegue de señalamientos críticos a la historia de las ideas. Algunas de las objeciones a esa historia de las ideas (internalista y algo descontextualizada) señalaban que se prestaba demasiada atención a la noción de "influencia" y se desdeñaba el peso de la selección, de la pragmática deliberada, consciente y fragmentaria de quienes importaban las ideas y de lo enrevesado y creativo de la recepción. El llamado de atención desde los años noventa del siglo XX apuntó a una recuperación de base contextualista (de los lenguajes, de los grupos, de las redes) pero también de la materialidad de los procesos de producción, circulación, recepción y lectura de las ideas. Todo ello es lo que hoy recibe el nombre de "historia intelectual", siempre con ambages y polémicas. ${ }^{27}$ El interés por el rol activo de los receptores de las ideas, de los traductores y de los impresores, de los editores y los promotores culturales redujo el foco de atención usualmente colocado sobre los autores metropolitanos y sus "influencias" locales, a las que se creía totales y compactas. Sobre el particular, vale la pena hacer notar cierta densidad geopolítica o anticolonial presente en el reclamo de reconocimiento de mayoría de edad epistemológica de los importadores o receptores de ideas, que escapaba en algo a las intenciones primigenias de Jauss ${ }^{28}$ : se trataba también de rehabilitar las lecturas creativas, flexibles, irreverentes y taimadas de las ideas del norte que fueron realizadas por los sujetos en el sur. ${ }^{29}$

Así, a inicios del siglo XXI, Daniel Lvovich produjo una historia de la producción, difusión, apropiación y adaptación de los Protocolos de los Sabios de Sión en Argentina. ${ }^{30}$ También mostró que el maurrasismo de los integrantes de La Nueva

\footnotetext{
27 Carlos Altamirano, "Ideas para un programa de historia intelectual”, en su libro Para un programa de historia intelectual y otros ensayos, Buenos Aires, Fondo de Cultura Económica, 2005.

${ }^{28}$ Hans Robert Jauss, Experiencia estética y hermenéutica literaria, Madrid, Taurus, 1992.

29 Puede verse con provecho las reflexiones aparecidas en la "Encuesta sobre el concepto de recepción" de la revista Políticas de la Memoria, n 8/9, 2008.

30 Daniel Lvovich. Nacionalismo y antisemitismo en la Argentina. Buenos Aires, Ediciones B, 2003.
} 


\section{La historia transnacional de las derechas argentinas en el siglo XX: ¿qué sabemos y qué podríamos saber?}

República era selectivo, por cuanto dejaban de lado aspectos como el monarquismo, que resultaban más ajenos -o directamente intragables- para el paladar político argentino. ${ }^{31}$ Tenemos hoy una gran cantidad de investigaciones que se dedican al estudio de las conexiones -formales o no- entre actores derechistas de Argentina y del exterior a lo largo del siglo XX. Estas innovaciones forman parte de una tendencia más general de la historiografía occidental desde la década de 1990 y que consiste en profundizar el interés por las entangled histories y las histoires croisées a través del tiempo y de los continentes. ${ }^{32}$

Pero si esa es una moda más general, lo que aquí vale la pena señalar es que el estudio transnacional de los derechistas fue resultado de la convergencia entre historiadores europeos y americanos. Así, los primeros desarrollaron perspectivas de investigación sobre la circulación transnacional de autores e ideas metropolitanas y colocaron en agenda cuestiones tales como las cercanías y conexiones entre el core fascism y los peripheral fascisms, las políticas franquistas en el exterior ${ }^{33}$, las sucesivas transferencias de ideas de pensadores como Charles Maurras o el neoliberalismo de von Mises y Karl Popper. Autores como Olivier Dard $^{34}$, Stein Larsen ${ }^{35}$ y Eugenia Scarzanella ${ }^{36}$ estimularon la constitución de redes de estudiosos de diversos países, lo cual ha redundado en mejores estudios de historia conectada y comparada de las derechas.

Por el lado de los historiadores americanos, tenemos hoy mucho mayor interés por conocer los procesos de contacto, las apropiaciones y las adaptaciones de las ideas provenientes de los centros ideológicos y de organizaciones de Estados Unidos y de países europeos. El estudio de la guerra fría en América latina en los últimos años ha ido modificando nuestra percepción de ese período. Libros como el compilado por Florencia Osuna y Valeria Galván ${ }^{37}$ ofrece pistas para pensar las imbricaciones

\footnotetext{
31 Daniel Lvovich. "La imagen del enemigo y sus transformaciones en La Nueva República (19281931)", Entrepasados, 17, 1999, Buenos Aires.

32 Michael Werner y Bénédicte Zimmerman. "Beyond comparison: histoire croisée and the challenge of reflexivity', History and theory, n. 45, 2006, pp. 30-50. Eliga Gould. "Entangled Histories, Entangled Worlds: The English-Speaking Atlantic as a Spanish Periphery", The American Historical Review, v. 112, n. 3, 2007, pp. 764-786.

${ }^{33}$ Celestino del Arenal,. Política exterior de España y relaciones con América Latina iberoamericanidad, europeización y atlantismo en la política exterior española. Madrid, Siglo XXI, 2011. Antonio Cañellas Mas. 'Las Políticas del Instituto de Cultura Hispánica, 1947-1953', Historia Actual Online, n. 33, 2014, pp. 77-91. Lorenzo Delgado Gómez-Escalonilla, Diplomacia franquista y política cultural hacia Iberoamérica, 1939-1953. Madrid, CSIC, 1988. Lorenzo Delgado Gómez-Escalonilla. Imperio de papel. Acción cultural y política exterior durante el primer franquismo. Madrid, CSIC, 1992.

34 Olivier Dard y Michel Grunewald (directores) Charles Maurras et l'étranger, l'étranger et Charles Maurras: l'Action française - culture, politique, société . Berna, Peter Lang 2009. Olivier Dard, y Nathalie Sévilla (directores). Le phénomène ligueur en Europe et aux Amériques. Metz, Presses Universitaires de Metz, 2011

35 Stein Ugelvik Larsen (editor). Fascism outside Europe. The European impulse against domestic conditions in the diffusion of global fascism. Nueva York, Columbia University Press, 2001.

${ }^{36}$ Eugenia Scarzanella (coordinadora), Fascisti in Sud America. Florencia, Casa Editrice Le Lettere, 2005

37 María Valeria Galván y María Florencia Osuna (compiladoras), La "Revolución Libertadora" en el marco de la Guerra Fría. La Argentina y el mundo durante los gobiernos de Lonardi y Aramburu, Rosario, Prohistoria Ediciones, 2018,
} 


\section{Ernesto Bohoslavsky}

entre los niveles nacional e internacional. Un trabajo pionero fue el Sandra McGee Deutsch $^{38}$ quien rastreó los intentos producidos en los primeros años veinte para constituir una suerte de Internacional Nacionalista en la que tuvo participación la Liga Patriótica Argentina. Trabajos como los de Federico Finchelstein ${ }^{39}$ o la compilación de Savarino y Bertonha ${ }^{40}$ nos permiten tener una idea más precisa de las cercanías y distancias entre los fascismos americanos y europeos. La (sobre)vida de los fascistas argentinos -y de sus camaradas europeos refugiados en el paísdespués de 1945 es un campo que ha tenido varios avances. Conocemos sobre la revista Dinámica social que en los años cincuenta fue un polo impulsor del neofascismo en Argentina y en Italia. ${ }^{41}$ Christian Buchrucker ha reconstruido algunas de esas redes internacionales del neofascismo y de antiguos colaboracionistas. ${ }^{42}$

Jorge Nállim ha estudiado el funcionamiento de las filiales argentinas del Congreso por la Libertad de la Cultura en los años cincuenta y sesenta ${ }^{43}$. Julieta Rostica ha comenzado a revisar el funcionamiento de la Confederación Anticomunista Latinoamericana en la década de 1970.44 Un libro que tuve la oportunidad de compilar junto a J. F. Bertonha ofrece un panorama de las conexiones entre actores de derecha de Brasil, Argentina, Chile, Uruguay y Paraguay entre 1917 y $1973 .{ }^{45}$

\footnotetext{
${ }^{38}$ Sandra McGee Deutsch, "Verso un'internazionale nazionalista: le relazioni internazionali della 'Liga Patriòtica Argentina', 1919-22", Ricerche di storia politica, n. 2, 2002, pp. 193-212.

${ }^{39}$ Federico Finchelstein. Fascismo trasatlántico. Ideología, violencia y sacralidad en Argentina y en Italia, 1919-1945. Buenos Aires, Fondo de Cultura Económica, 2010.

${ }^{40}$ Franco Savarino Roggero, y João Fábio Bertonha (coordinadores), El fascismo en Brasil y América Latina: ecos europeos y desarrollos autóctonos. México, INAH, Conaculta, 2013

${ }^{41}$ Noemí Girbal-Blacha. "Armonía y contrapunto intelectual: Dinámica Social (1950-1965)", en Girbal-Blacha, Noemí y Quattrocchi-Woisson, Diana (directoras), Cuando opinar es actuar. Revistas argentinas del siglo XX. Buenos Aires, Academia Nacional de la Historia, 1999. Celina Albornoz. "Fascistas entre Italia y Argentina. Migraciones y política en la segunda posguerra: el caso de Carlo Scorza y Dinámica Social". Tesina de Licenciatura, Universidad Nacional del Litoral y Università Ca' Foscari di Venezia, Santa Fe, 2017.

${ }^{42}$ Christian Buchrucker. "Los nostálgicos del 'Nuevo Orden' europeo y sus vinculaciones con la cultura política argentina", en Ignacio Klich (editor) Sobre nazis y nazismo en la cultura argentina, College Park Hispamérica y Maryland University, 2002, pp. 51-103.

${ }^{43}$ Jorge Nállim. "Redes transnacionales, antiperonismo y Guerra Fría: los orígenes de la Asociación Argentina por la Libertad de la Cultura". Prismas. Revista de Historia Intelectual, n. 16, 2012, pp.121141. "Local Struggles, Transnational Connections: Latin American Intellectuals and the Congress for Cultural Freedom", en Tina Chen y David Churchill (eds.). The Material of World History. Londres, Routledge, 2015.

44 Julieta Rostica. "La Confederación Anticomunista Latinoamericana y las Fuerzas Armadas. Guatemala y los años setenta", ponencia presentada en el II Coloquio Pensar las derechas en América Latina en el siglo XX. Universidad Nacional de General Sarmiento, Los Polvorines, 2016.

${ }^{45}$ João Fábio Bertonha y Bohoslavsky, Ernesto (editores). Circule por la derecha. Percepciones, redes y contactos entre las derechas sudamericanas, 1917-1973. Los Polvorines, Universidad Nacional de General Sarmiento, 2016.
} 


\section{La historia transnacional de las derechas argentinas en el siglo XX: ¿qué sabemos y qué podríamos saber?}

Colegas como Luis Herrán ${ }^{46}$, Mario Santiago Jiménez ${ }^{47}$ y Magdalena Broquetas ${ }^{48}$ han puesto de manifiesto los procesos de circulación de jóvenes de derecha, así como de sacerdotes entre Argentina, Uruguay y México entre los años cincuenta y setenta del siglo XX.

Una de las áreas más interesantes de la historiografía argentina de los últimos veinte años se ha dedicado al estudio de los procesos de constitución, importación, legitimación y choque de saberes especializados. Se trata de un campo que nace bajo la égida de la historia transnacional, dado que no pre-existe a los años noventa. Antes de ello había una historia internalista de las ciencias e historia de las ideas desde ya, pero la historia de los saberes expertos remite a otras preguntas y a otras fuentes. Hace veinte años Eduardo Zimmermann ${ }^{49}$ propuso una agenda de investigaciones acerca de la constitución de elites del conocimiento social y la institucionalización de las disciplinas sociales que ocurrieron a finales del siglo XIX. Ese proceso permitió el estudio de la llegada de criminólogos y de la criminología italiana encarnada en figuras como Enrico Ferri y Cesare Lombroso, que tuvieron un notable y destacado grupo de seguidores y adaptadores en Argentina.

El análisis de las redes de científicos y sus vínculos con organizaciones de derecha se ha diversificado en los últimos años, incorporando nuevos temas y sujetos. En particular, se ha puesto el ojo sobre las redes de académicos y de policy-makers que unían a Argentina con la España franquista ${ }^{50}$ así como los hubs de esas redes: el Instituto de Cultura Hispánica, la Escuela sevillana de historia de la Universidad Nacional de Cuyo en Mendoza $^{51}$ y sus protagonistas, los académicos 52 y los

\footnotetext{
46 "Las guerrillas blancas: anticomunismo transnacional e imaginarios de derechas en Argentina y México. 1954-1972”. Quinto Sol, 19, 2015, pp. 1-26

47 Mario Virgilio Santiago Jiménez. Juventudes católicas contra la 'amenaza comunista'. Estudio comparativo entre el Yunque de México y Tacuara de Argentina (1953-1964). Tesis del Doctorado en Historia del Instituto de Investigaciones Dr. José María Luis Mora, México D. F, 2016

48 Magdalena Broquetas. "Entre la reacción y la restauración. Derechas y violencia en los inicios de la crisis de 1960", Estudos Ibero-americanos, vol. 42, n. 1, 2016, pp. 142-166.

49 Eduardo Zimmermann. Los liberales reformistas. La cuestión social en la Argentina 1890-1916. Buenos Aires, Sudamericana y Universidad San Andrés, 1995

50 Beatriz, Figallo (editora) Desarrollismo, Franquismo y neohispanidad. Historias conectadas entre España, América Latina y Argentina. Buenos Aires, Teseo, 2018.

51 María Celina Fares. "Tradición y reacción en el sesquicentenario. La escuela sevillana mendocina", Prismas. Revista de Historia Intelectual, n.15, 2011, pp. 87-104. "Conexiones atlánticas entre el franquismo y la periferia a propósito del Sesquicentenario", en Betancour Mendieta, Alexander (ed.) Escritura de la Historia y Política. El sesquicentenario de la Independencia en América Latina, Lima, Instituto Francés de Estudios Andinos. México, IFEA, FCSyH., Universidad Autónoma de Potosí, 2016 y “Las caras del hispanismo: tránsitos y perfiles de intelectuales de derecha en la posguerra', Nuevo Mundo Mundos Nuevos, 2017.

52 Patricia Orbe. "Sociabilidad tradicionalista en la Argentina: La ofensiva tomista en la trama académica de los años setenta", Anuario de la Escuela de Historia Virtual, 2016, pp. 98 - 113.
} 


\section{Ernesto Bohoslavsky}

especialistas en educación ${ }^{53}$ y planificación urbana. ${ }^{54}$ En esa perspectiva, Juan Besoky ha seguido la pista a colaboracionistas franceses que se reciclaron como académicos en Argentina y que encontraron un nido en el peronismo y en algunos ámbitos académicos. ${ }^{55}$

El estudio de los think tanks y de los expertos es una de las áreas del campo de estudios de las derechas que ha mostrado últimamente resultados más interesantes. Gracias al diálogo entre la sociología de los expertos, la historia de las profesiones y el análisis de las redes intelectuales, tenemos hoy una bibliografía muy innovadora. Si bien en la década de 1990 aparecieron los primeros trabajos sobre los think tanks y sus vínculos con grupos políticos y empresariales, fue en la década del 2000 que se vivió una verdadera expansión de esta temática. ${ }^{56}$ Tenemos aquí al sujeto ideal del abordaje transnacional por cuanto es transnacional en su funcionamiento, en su reclutamiento, en la difusión de sus ideas, en los diagnósticos y sugerencias de policy-making y en su búsqueda y obtención de fondos. Trabajos como los de Hernán Ramírez ${ }^{57}$ sobre la FIEL y la Fundación Mediterránea en Argentina y sobre el IPÊS en Brasil permiten percibir el funcionamiento de redes transnacionales desde los años sesenta, así como discutir sobre bases más sólidas las vinculaciones entre la financiación estadounidense, el anticomunismo local, las Fuerzas Armadas y los grupos empresariales. Aunque naturalmente orientada hacia el estudio de centros de pensamiento actuales como la Fundación Libertad de Rosario o las fundaciones Sofía y Pensar que terminaron confluyendo en el macrismo, tenemos en este campo un conjunto de investigaciones y publicaciones a las que vale la pena prestar atención para acercarnos al pasado de las derechas.

\footnotetext{
${ }^{53}$ Laura Graciela Rodríguez. "Los católicos desarrollistas en Argentina. Educación y planeamiento en los años de 1960", Diálogos, v. 17, n.1, 2013, p. 155-184. "Los hispanismos en Argentina: publicaciones, redes y circulación de ideas", Cahiers des Amériques Latines, 79, 2015, pp. 97-114. "La 'subversión científica' en las universidades de Argentina e Hispanoamérica", Nuevo Mundo Mundos Nuevos, 2016, pp. 11-25.

${ }^{54}$ Gabriela Gomes. "Vivienda social en dictaduras. Actores, discursos, políticas públicas y usos propagandísticos en las Regiones Metropolitanas de Buenos Aires (1966-1983) y Santiago de Chile (1973-1989)", tesis de Doctorado, Universidad de Buenos Aires, 2018.

55 Juan Luis Besoky. "Trayectorias intelectuales y redes trasnacionales en la derecha peronista: los casos de Jacques Marie de Mahieu y Pierre Daye", ponencia presentada en el II Coloquio Pensar las derechas en América Latina en el siglo XX, Universidad Nacional de General Sarmiento, Los Polvorines, 2016 y "De Maurras a Perón. La trayectoria intelectual de Jaime María de Mahieu y su influencia en el nacionalismo argentino", ponencia presentada en el III Coloquio Pensar las derechas en América Latina en el siglo XX, UFMG, Belo Horizonte, 2018.

${ }^{56}$ Sabina Frederic, Osvaldo Graciano, y Germán Soprano (coordinadores) El Estado argentino y las profesiones liberales, académicas y armadas. Rosario, Prohistoria Ediciones, 2010. Sergio Morresi y Gabriel Vommaro (compiladores) Saber lo que se hace. Expertos y política en la Argentina. Buenos Aires, Prometeo y Universidad Nacional de General Sarmiento, 2012. Mariano Plotkin y Eduardo Zimmermann (compiladores) Los saberes del Estado. Buenos Aires, Edhasa, 2012. Federico Neiburg y Mariano Plotkin (editores) Intelectuales y expertos. La constitución del conocimiento social en la Argentina. Buenos Aires, Paidós, 2004, pp. 15-30.

57 Hernán Ramírez. Corporaciones en el poder. Institutos y acción política en Brasil y Argentina. IPÊS, FIEL y Fundación Mediterránea. Buenos Aires, Lenguaje claro Editora, 2007.
} 


\section{La historia transnacional de las derechas argentinas en el siglo XX: ¿qué sabemos y qué podríamos saber?}

\section{Conclusiones y perspectivas}

Desde el seminal texto de Pierre Bourdieu aparecido en 1990, la dimensión trasnacional de los bienes simbólicos ha ido ganando centralidad en las ciencias sociales. ${ }^{58}$ Como señalaron Mariano Plotkin y Federico Neiburg, el estudio de la dimensión transnacional de los sujetos y procesos remite a la vez a dos aspectos que están conectados. ${ }^{59}$ En primer lugar, hace referencia al carácter transnacional del objeto de estudio que son -especial o primordialmente- aquellos sujetos que mostraron capacidad y a veces voluntad de atravesar fronteras nacionales o que pensaron para sus prácticas un escenario que excedía al territorio nacional. De allí la concentración de las investigaciones sobre los viajeros y sus relatos, los libros y la industria editorial, las corrientes de ideas y los conceptos con pretensiones universalistas, los think tanks, etc. Pero en segundo lugar, lo "transnacional" remite a la metodología que se usa para estudiarlos: ello implica que los investigadores desplacen el acento que normalmente está colocado en la comprensión de lo que eran ciertos libros, ciertas ideas, ciertos movimientos políticos o ciertos autores (una por así decir ontología) y lo trasladen hacia temas menos esencialistas y más relacionales, como son el estudio de la difusión de los bienes, conceptos y diagnósticos, así como de los intereses, obstáculos y facilitadores de esa circulación transnacional, de las formas de recepción de las obras, del peso de los importadores y de la eficiencia de los usuarios en la fijación de sentidos. La atención a la transnacionalidad de los sujetos no es sólo una metodología sino también un modo de construir los problemas y de imaginar históricamente a los sujetos.

Una de las evidencias que aparece de este primer recorrido sobre la historia transnacional de las derechas argentinas es el fuerte peso que tuvieron autores no argentinos. Ello se debió sin dudas al carácter subdesarrollado de nuestra propia academia, pero sobre todo al tipo de temas. Realizar una buena historia transnacional implica la posesión de ciertos recursos económicos e intelectuales que no están universalmente disponibles. Así, requiere de un clima académico en el que se promueva el estudio de realidades nacionales que no sean la propia: de allí que este tipo de investigaciones normalmente hayan tenido un nido más cálido en los Latin American Studies o los Area Studies, que alientan este tipo de investigaciones que abarcan varios países a la vez. Robert Potash y Sandra McGee están más identificados como latinoamericanistas que como argentinólogos. Esas pesquisas requieren también de mayores fondos de investigación por cuanto implican visitar accesos documentales presentes en varios países o localidades: seguirles la pista a esos actores implica, entonces, disponibilidad de recursos financieros, idiomáticos e institucionales para facilitar ese desplazamiento físico por parte de quien investiga. Y si bien internet ha facilitado muchas cosas, no todas las soluciones están

\footnotetext{
58 Pierre Bourdieu, "Las condiciones sociales de la circulación de las ideas", en su libro Intelectuales, política y poder. Buenos Aires, Eudeba, 2003, pp. 159-170 (orig. 1990)

${ }^{59}$ Neiburg y Plotkin. “Intelectuales.....", op. cit. pp. 15-30.
} 


\section{Ernesto Bohoslavsky}

al alcance de un mouse. Una investigación como la que realizó Loris Zanatta ${ }^{60}$ sobre las vinculaciones diplomáticas oficiales y paralelas que desarrolló el peronismo clásico implicó consultar archivos de una decena de países de América y de Europa durante mucho tiempo: con independencia de la valoración crítica sobre los resultados de la obra, no puede negarse la cantidad de horas de consulta presentadas en La Internacional justicialista ni que ese tipo de esfuerzos requieren de inversiones usualmente difíciles de obtener para proyectos de historia financiados en Argentina. Con ello no quiero caer en determinismos materialistas, sino apuntar al hecho de que el desarrollo de cierta agenda está asociado a la provisión de recursos para su despliegue en el tiempo. No es un problema meramente presupuestario desde ya: una buena historia transnacional requiere también de mejor conocimiento de otras realidades pasadas, pero también de otras historiografías y tradiciones de reflexión de otros países: eso requiere dinero, pero no sólo dinero.

Los primeros estudios sobre las derechas argentinas en los años ochenta usaban de manera recurrente la noción de "influencia" para explicar los procesos de transferencia de ideas. Por ello documentaron la llegada de cuerpos de ideas como el fascismo, el prusianismo, el integrismo vaticano, el monetarismo, o el franquismo, pero se interesaron menos por entender las razones de esas importaciones, los usos periféricos de las ideas centrales. En los últimos quince años el estudio de estos actores de derecha creció al tomar prestadas herramientas provenientes de la historia de los intelectuales, del libro y de la edición, de los exilios y de los procesos de traducción cultural e idiomática. Discusiones como las iniciadas en los años setenta por Roberto Schwarz y Silviano Santiago en Brasil permitieron pensar mejor la dinámica incontrolada de lo propio y lo foráneo, la apropiación y la desviación de las ideas. ${ }^{61}$ Los aportes de la historia intelectual facilitaron la reconstrucción de la materialidad y la dinámica de los procesos de circulación y sociabilidad internacional de los derechistas en el siglo XX: la historia de la circulación no reemplaza a la historia de la construcción de significados sino que es una entrada fructífera y legítima para entender a los actores políticos e intelectuales en un contexto sobre el que operan y que a la vez sobre ellos actúa. Con estas herramientas no sólo se verifica la existencia de vínculos internacionales, sino que se buscan las razones -no siempre conscientes, explícitas ni unívocas- por las cuales se importan ciertas doctrinas y estrategias, qué se selecciona de esos cuerpos de ideas y por qué se lo hace.

Gracias a las investigaciones sobre las redes internacionales podemos decir que todos los actores de derecha de Argentina (pero no sólo ellos) tuvieron lazos con actores del exterior a lo largo del siglo XX. Pero con eso no avanzaríamos mucho. Creo que es necesario profundizar esa apreciación e identificar tipos de

\footnotetext{
${ }^{60}$ Loris Zanatta La Internacional Justicialista. Auge y ocaso de los sueños imperiales de Perón. Buenos Aires, Sudamericana, 2013.

${ }^{61}$ La reconstrucción de esos debates la ofrece Elías Palti en el capítulo 1 de su libro El tiempo de la política: el siglo XIX reconsiderado. Buenos Aires, Siglo XXI Editores, 2007.
} 


\section{La historia transnacional de las derechas argentinas en el siglo XX: ¿qué sabemos y qué podríamos saber?}

transferencias y de conexiones internacionales. Por un lado, podemos percibir aquellas conexiones más formalizadas, rutinizadas e institucionalizadas. La Iglesia, por ejemplo, tiene formas institucionalizadas de transmitir doctrina a través de encíclicas y declaraciones, que van del Vaticano a los episcopados nacionales y de éstos a las diócesis y de éstas a los sacerdotes y de éstos a los laicos. La transmisión trasnacional de doctrina de la Iglesia es sistemática, y es institucional. Posee un centro ideológico formal, que intenta ejercer relaciones de dominación respecto de los actores subordinados en los niveles nacional, provincial y local. Y aunque hoy sabemos que la pretensión de univocidad siempre encontró límites y objeciones en otros actores, nada impide que sea percibida.

Otros actores que también solemos clasificar en la derecha del arco ideológico, en cambio, participan de redes con menor nivel de formalidad (y verticalismo) lo cual trae consigo procesos de transmisión más arduos, espontáneos, competidos, creativos e inevitablemente polisémicos. Son conexiones menos sistemáticas, con menor reconocimiento -en muchos casos clandestinas- dado que no siempre tienen un centro universal ni permanentemente respetados. Así, las vinculaciones de la Alianza Juvenil Nacionalista (1937-1943) o del diario Crisol (1932-1938) con ideas -y dinero- provenientes de las embajadas alemana e italiana no descansaban en lazos formales sino secretos y mucho más lábiles que las que unían a los obispos con el Vaticano.

Los avances producidos por el diálogo con la historia intelectual invitan a profundizar en torno a las formas de circulación transnacional en, por lo menos, cuatro sentidos:

a) Lo que podríamos llamar la circulación del salmón, esto es, aquella que va en el sentido geográfico contrario al dominante. Sabemos muy poco sobre los impactos y recepciones que hubo en los países metropolitanos de las innovaciones doctrinarias y de las prácticas políticas originadas en el sur del mundo. Los temas a explorar no son sencillos, pero tampoco son imposibles si damos con las fuentes pertinentes. Tenemos algunos trabajos que dan cuenta de cómo la Falange española interpretó al peronismo clásico y el tipo de vínculos que tuvo con Perón mientras estuvo exiliado en Madrid ${ }^{62}$, pero no mucho más. Hay mucho margen para avanzar en un estudio de los exilios de argentinos de derechas en Europa y en Estados Unidos (e incluso en Uruguay): pienso en el caso de Walter Beveraggi Allende, economista cordobés que luego de un paso por el laborismo fue perseguido por el régimen peronista y se refugió en Estados Unidos en los años cincuenta: a su regreso se constituyó en una de las voces más importantes del antisemitismo académico argentino ${ }^{63}$. No sabemos casi nada

${ }^{62}$ Carolina Cerrano. "Las imágenes de la Argentina peronista en la prensa franquista (1945-1948)", Revista de Historia Americana y Argentina, n. 42-43, 2007-2008; "El filoperonismo falangista", Ayer, v. 96, n. 4, 2014, pp. 131-154.

${ }^{63}$ Ernesto Bohoslavsky. "Invención y circulación del Plan Andinia (Argentina y Chile, 1960-1976)". En: Ernesto Bohoslavsky, Marina Franco, Mariana Iglesias y Daniel Lvovich (eds.), Problemas de historia reciente en el Cono Sur, Buenos Aires, Universidad Nacional de General Sarmiento y Prometeo Libros, tomo II, 2010, pp. 177-200. 


\section{Ernesto Bohoslavsky}

sobre las perspectivas que generaron entre los hombres de la extrema derecha europea las dictaduras lideradas por los generales Onganía en 1966 y Videla en 1976: ¿qué lecturas políticas inspiró la puesta en marcha de las operaciones de "limpieza" extrema de los comunistas que reclamaban desde el inicio de la guerra fría?

b) La circulación horizontal o sur/sur (o entre actores latinoamericanos). Este estado de la cuestión mostró que realmente sabemos muy poco sobre los procesos de colaboración entre organizaciones de derecha y empresariales de países sudamericanos a lo largo del siglo XX. Conocemos algo sobre los vínculos de las Fuerzas Armadas sudamericanas en las décadas de 1960 y 1970, en particular lo referido a la elaboración y puesta en marcha del Plan Cóndor y los ya mencionados trabajos de Ariel Armony y Julieta Rostica sobre las vinculaciones del Ejército argentino con el guatemalteco. Pero quizás estos aspectos tengan que pensarse más como parte de la historia de las relaciones inter-estatales que de la historia de las conexiones derechistas propiamente dicha. Nos queda por transitar mucho camino para conocer más sobre las alianzas derechistas sudamericanas en las que participaron actores argentinos, como las redes de amigos del peronismo, las bandas anticomunistas de fines de los años sesenta ${ }^{64}$, los think tanks de los noventa, entre otros.

c) Las percepciones cruzadas sur/sur. Este estado de la cuestión mostró que los actores argentinos prestaron mucha atención a los sucesos europeos (la Revolución rusa, el ascenso del fascismo, la guerra civil española, la segunda guerra mundial, la renovación del catolicismo, la expansión del neoliberalismo, etc.). Lo que nos queda por revisar con mayor insistencia es el tipo de diagnósticos que grupos de derecha argentinos ofrecían de la situación política en los países vecinos ${ }^{65}$. Fascinados con la opinión de que emitieron periódicos como La Nueva República, Criterio, Sur, Bandera argentina, La Nación, Azul y Blanco, Cabildo y Verbo sobre la situación europea, hemos prestado poca atención a las representaciones sobre los problemas y procesos vividos en la región, como la guerra cristera ${ }^{66}$, las dictaduras reformistas de los años sesenta en Bolivia y Perú, la experiencia de la Unidad Popular chilena ${ }^{67}$, entre otros temas.

\footnotetext{
${ }^{64}$ Como hizo Magdalena Broquetas. La trama autoritaria. Derechas y violencia en Uruguay (19581966). Montevideo, Ediciones de la Banda Oriental, 2014 y "Una lucha sin fronteras: la derecha 'democrática' y la embestida anticomunista en Uruguay de finales de la década de 1950", Cahiers des Amériques Latines, v. 79, n. 2, París, 2015, pp. 75-96.

65 Como intentamos hacer con las perspectivas argentinas sobre el Estado Novo varguista. Cfr. Ernesto Bohoslavsky y Martín Vicente. "El Estado Novo a ojos de liberales de Argentina y de Brasil (1937-1946)", Revista de História Comparada, v. 8, n. 2, Río de Janeiro, 2014, pp. 226-253.

66 Miranda Lida "La cuestión mexicana en el catolicismo argentino de la década de 1920", en Jean Meyer (comp.), Las naciones frente al conflicto religioso en México (1926-1929). México, CIDE y Tusquets, 2010, pp. 247-264.

${ }^{67}$ Patricia Orbe. "La 'salida militar' como única opción frente al comunismo: la experiencia chilena desde la mirada nacionalista católica argentina (1970-1974), Contemporánea, v.3, n. 3, 2012, pp. 115131.
} 


\section{La historia transnacional de las derechas argentinas en el siglo XX: ¿qué sabemos y qué podríamos saber?}

d) Convendría también prestar más atención a aquello que la perspectiva transnacional nos inhibe de percibir. Recordemos que el giro transnacional apuntó a des-provincializar las miradas y a destacar las conexiones que han tenido las personas y las instituciones a lo largo del tiempo, de manera tal de desnaturalizar los límites nacionales. Pero asumir como transnacionales a los sujetos puede terminar haciendo aquello que se desea evitar puesto que vuelve a recordarnos la existencia de Estados nacionales -aunque esta vez vulnerables y no auto-contenidos, desde ya-. En ese sentido, el estudio de la dimensión transnacional corre el riesgo de dotar a los pasados nacionales de una homogeneidad que quizás no era tan espesa ni tan evidente. Un anticuerpo contra ese riesgo es explorar los contactos que existieron entre integrantes de organizaciones de alcance regional o provincial y el exterior, redes que muchas veces prescindieron -o limitaron a lo mínimo y necesario- el filtro de Buenos Aires.

\section{Bibliografía}

A.A.V.V. "Dossier Encuesta sobre el concepto de recepción”, Políticas de la Memoria, $\mathrm{n}^{\circ}$ 8/9, Buenos Aires, 2008.

Celina Albornoz. "Fascistas entre Italia y Argentina. Migraciones y política en la segunda posguerra: el caso de Carlo Scorza y Dinámica Social”. Tesina de la Licenciatura en Historia, Universidad Nacional del Litoral y Università Ca' Foscari di Venezia, Santa Fe, 2017.

Carlos Altamirano, Para un programa de historia intelectual y otros ensayos, Buenos Aires, Fondo de Cultura Económica, 2005.

Gineth Álvarez Satizábal. Ideas macro, acciones micro. Actores y redes del catolicismo integral en la educación de Argentina y Colombia (1930 y 1940). Tesis de Maestría, Buenos Aires, Universidad Nacional de San Martín, 2015.

Celestino del Arenal, Política exterior de España y relaciones con América Latina iberoamericanidad, europeización y atlantismo en la política exterior española. Madrid, Siglo XXI, 2011.

Ariel Armony, La Argentina, los Estados Unidos y la cruzada anticomunista en América Central, 1977-1984, Bernal, Universidad Nacional de Quilmes, 1999.

María Inés Barbero y Fernando Devoto, Los nacionalistas (1910-1932). Buenos Aires, Centro Editorial de América latina, 1983 


\section{Ernesto Bohoslavsky}

João Fábio Bertonha y Ernesto Bohoslavsky (editores). Circule por la derecha. Percepciones, redes y contactos entre las derechas sudamericanas, 1917-1973. Los Polvorines, Universidad Nacional de General Sarmiento, 2016.

Juan Luis Besoky. "Trayectorias intelectuales y redes trasnacionales en la derecha peronista: los casos de Jacques Marie de Mahieu y Pierre Daye", ponencia presentada en el II Coloquio Pensar las derechas en América Latina en el siglo XX, Universidad Nacional de General Sarmiento, Los Polvorines, 2016.

Juan Luis Besoky. “De Maurras a Perón. La trayectoria intelectual de Jaime María de Mahieu y su influencia en el nacionalismo argentino", ponencia presentada en el III Coloquio Pensar las derechas en América Latina en el siglo XX, UFMG, Belo Horizonte, 2018.

Jessica Blanco, "Las distintas juventudes de la iglesia en Argentina a mediados del siglo XX. Los casos de la Juventud de Acción Católica y la Juventud Obrera Católica", Letras Históricas, 4, Guadalajara, 2011, pp. 139-160

Jessica Blanco, Modernidad conservadora y cultura política: la Acción Católica Argentina (1931-1941), Córdoba, Universidad Nacional de Córdoba, 2008.

Ernesto Bohoslavsky. "Invención y circulación del Plan Andinia (Argentina y Chile, 1960-1976)". En: Ernesto Bohoslavsky, Marina Franco, Mariana Iglesias y Daniel Lvovich (eds.), Problemas de historia reciente en el Cono Sur, Buenos Aires, Universidad Nacional de General Sarmiento y Prometeo Libros, tomo II, 2010, pp. 177-200.

Ernesto Bohoslavsky y Martín Vicente. "El Estado Novo a ojos de liberales de Argentina y de Brasil (1937-1946)", Revista de História Comparada, v. 8, n. 2, Río de Janeiro, 2014, pp. 226-253.

Pierre Bourdieu, Intelectuales, política y poder. Buenos Aires, Eudeba, 2003.

Magdalena Broquetas. La trama autoritaria. Derechas y violencia en Uruguay (19581966). Montevideo, Ediciones de la Banda Oriental, 2014.

Magdalena Broquetas. "Una lucha sin fronteras: la derecha 'democrática' y la embestida anticomunista en Uruguay de finales de la década de 1950", Cahiers des Amériques Latines, v. 79, n. 2, París, 2015, pp. 75-96.

Magdalena Broquetas. "Entre la reacción y la restauración. Derechas y violencia en los inicios de la crisis de 1960", Estudos Ibero-americanos, vol. 42, n. 1, p. 2016, 142166.

Christian Buchrucker. Nacionalismo y peronismo. La Argentina en la crisis ideológica mundial. Buenos Aires: Sudamericana, 1987. 


\section{La historia transnacional de las derechas argentinas en el siglo XX: ¿qué sabemos y qué podríamos saber?}

Christian Buchrucker. "Los nostálgicos del 'Nuevo Orden' europeo y sus vinculaciones con la cultura política argentina", en Ignacio Klich (editor) Sobre nazis y nazismo en la cultura argentina, College Park Hispamérica y Maryland University, 2002, pp. 51-103.

Barry Cannon. The Right in Latin America: Elite Power, Hegemony and the Struggle for the State, Londres, Routledge, 2016.

Antonio Cañellas Mas. "Las políticas del Instituto de Cultura Hispánica, 1947-1953”, Historia Actual Online, n. 33, 2014, pp. 77-91.

Carolina Cerrano. "Las imágenes de la Argentina peronista en la prensa franquista (1945-1948)”, Revista de Historia Americana y Argentina, n. 42-43, 2007-2008.

Carolina Cerrano. "El filoperonismo falangista”, Ayer, v. 96, n. 4, 2014, pp. 131-154.

Facundo Cersósimo. "El Proceso fue liberal” Los tradicionalistas católicos argentinos y el Proceso de Reorganización Nacional (1976-1983). Tesis del Doctorado, Buenos Aires, Universidad de Buenos Aires, 2015.

Olivier Dard y Michel Grunewald (directores) Charles Maurras et l'étranger, l'étranger et Charles Maurras: l'Action française - culture, politique, société. Berna, Peter Lang 2009.

Olivier Dard y Nathalie Sévilla (directores). Le phénomène ligueur en Europe et aux Amériques. Metz, Presses Universitaires de Metz, 2011

Lorenzo Delgado Gómez-Escalonilla, Diplomacia franquista y política cultural hacia Iberoamérica, 1939-1953. Madrid, CSIC, 1988.

Lorenzo Delgado Gómez-Escalonilla. Imperio de papel. Acción cultural y política exterior durante el primer franquismo. Madrid, CSIC, 1992.

María Celina Fares. "Tradición y reacción en el sesquicentenario. La escuela sevillana mendocina", Prismas. Revista de Historia Intelectual, n.15, 2011, pp. 87-104.

María Celina Fares. "Conexiones atlánticas entre el franquismo y la periferia a propósito del Sesquicentenario", en Alexander Betancour Mendieta (editor) Escritura de la Historia y Política. El sesquicentenario de la Independencia en América Latina, Lima y México, Instituto Francés de Estudios Andinos y Universidad Autónoma de Potosí, 2016.

María Celina Fares. "Las caras del hispanismo: tránsitos y perfiles de intelectuales de derecha en la posguerra', Nuevo Mundo Mundos Nuevos. 2017 URL: http://nuevomundo.revues.org/70537 


\section{Ernesto Bohoslavsky}

Beatriz Figallo (editora). Desarrollismo, Franquismo y neohispanidad. Historias conectadas entre España, América Latina y Argentina. Buenos Aires, Teseo, 2018.

Federico Finchelstein. Fascismo trasatlántico. Ideología, violencia y sacralidad en Argentina y en Italia, 1919-1945. Buenos Aires, Fondo de Cultura Económica, 2010.

Sabina Frederic, Osvaldo Graciano, y Germán Soprano (coord.) El Estado argentino y las profesiones liberales, académicas y armadas. Rosario, Prohistoria Ediciones. 2010.

María Valeria Galván y María Florencia Osuna (comp.), La "Revolución Libertadora" en el marco de la Guerra Fría. La Argentina y el mundo durante los gobiernos de Lonardi y Aramburu, Rosario, Prohistoria Ediciones, 2018,

Noemí Girbal-Blacha. "Armonía y contrapunto intelectual: Dinámica Social (19501965)", en Noemí Girbal-Blacha y Diana Quattrocchi-Woisson (dir.), Cuando opinar es actuar. Revistas argentinas del siglo XX. Buenos Aires, Academia Nacional de la Historia, 1999.

Gabriela Gomes. Vivienda social en dictaduras. Actores, discursos, políticas públicas y usos propagandísticos en las Regiones Metropolitanas de Buenos Aires (1966-1983) y Santiago de Chile (1973-1989). Tesis de doctorado en Historia, Buenos Aires, Universidad de Buenos Aires, 2018.

Eliga Gould. "Entangled Histories, Entangled Worlds: The English-Speaking Atlantic as a Spanish Periphery", The American Historical Review, v. 112, n. 3, 2007, pp. 764786.

Luis Herrán Ávila. "Las guerrillas blancas: anticomunismo transnacional e imaginarios de derechas en Argentina y México. 1954-1972". Quinto Sol, 19, 2015, pp. 1-26.

Hans Robert Jauss, Experiencia estética y hermenéutica literaria, Madrid, Taurus, 1992.

Stein Ugelvik Larsen (editor) Fascism outside Europe. The European impulse against domestic conditions in the diffusion of global fascism. Nueva York, Columbia University Press, 2001.

Miranda Lida "La cuestión mexicana en el catolicismo argentino de la década de 1920", en Jean Meyer (compilador), Las naciones frente al conflicto religioso en México (1926-1929). México, CIDE y Tusquets, 2010, pp. 247-264.

Miranda Lida, "Trazos francófilos en la cultura católica argentina de entreguerras", Boletín PolHis, v. 7, 2014, p. 246-251. 


\section{La historia transnacional de las derechas argentinas en el siglo XX: ¿qué sabemos y qué podríamos saber?}

Miranda Lida. “De Manuel Gálvez a Jacques Maritain. Hispanofilia y francofilia en el catolicismo argentino de la primera mitad del siglo XX", Itinerantes. Revista de Historia y Religión, vol. 7, 2017, pp. 61-81.

Daniel Lvovich. "La imagen del enemigo y sus transformaciones en La Nueva República (1928-1931)”, Entrepasados, n. 17, 1999, Buenos Aires.

Daniel Lvovich Nacionalismo y antisemitismo en la Argentina. Buenos Aires: Ediciones B, 2003.

Fortunato Mallimaci El catolicismo integral en la Argentina, 1930-1946. Buenos Aires, Fundación Simón Rodriguez y Biblos, 1988.

Diego Mauro. "Multitudes y movilizaciones católicas en la Argentina de entreguerras. Cuestiones metodológicas e historiográficas", PolHis, № 8, 2011, pp. 90-96.

Diego Mauro y Miranda Lida (coordinadores). Catolicismo y sociedad de masas en Argentina: 1900-1950. Rosario, Prohistoria, 2009.

Daniel Mazzei, "La misión militar francesa en la Escuela Superior de Guerra y los orígenes de la guerra sucia”, Revista de Ciencias Sociales, n. 13, 2002, pp. 105-137.

Daniel Mazzei, Bajo el poder de la caballería: El ejército argentino (1962-1973). Buenos Aires, Eudeba, 2012.

Sandra McGee Deutsch, "Verso un'internazionale nazionalista: le relazioni internazionali della 'Liga Patriòtica Argentina', 1919-22", Ricerche di storia politica, n. 2, 2002, pp. 193-212.

Sergio Morresi y Gabriel Vommaro (compiladores) Saber lo que se hace. Expertos y política en la Argentina. Buenos Aires, Prometeo y Universidad Nacional de General Sarmiento. 2012

Jorge Nállim. "Redes transnacionales, antiperonismo y Guerra Fría: los orígenes de la Asociación Argentina por la Libertad de la Cultura". Prismas. Revista de Historia Intelectual, n. 16, 2012, pp.121-141.

Jorge Nállim. "Local Struggles, Transnational Connections: Latin American Intellectuals and the Congress for Cultural Freedom", en Tina Chen y David Churchill (editores). The Material of World History. Londres, Routledge, 2015.

Federico Neiburg y Mariano Plotkin (editores). Intelectuales y expertos. La constitución del conocimiento social en la Argentina. Buenos Aires: Paidós, 2004. 


\section{Ernesto Bohoslavsky}

Patricia Orbe. "La 'salida militar' como única opción frente al comunismo: la experiencia chilena desde la mirada nacionalista católica argentina (1970-1974)", Contemporánea, v.3, n. 3, 2012, pp. 115-131.

Patricia Orbe. "Le nationalisme argentin et les débats sur les droites dans le Cône Sud de l'Amérique Latine de la seconde moitié du XXème siècle: progrès et défis dans le champ de la recherche historiographique", Cahier d'histoire immédiate, n. 46, 2014, pp. 51-65.

Patricia Orbe. "Sociabilidad tradicionalista en la Argentina: La ofensiva tomista en la trama académica de los años setenta", Anuario de la Escuela de Historia Virtual, 2016, pp. 98-113.

Elías Palti, El tiempo de la política: el siglo XIX reconsiderado. Buenos Aires, Siglo XXI Editores, 2007.

Mariano Plotkin y Eduardo Zimmermann (compiladores) Los saberes del Estado. Buenos Aires, Edhasa, 2012

Esteban Pontoriero. "Pensamiento militar y legislación de defensa en la Argentina: la caracterización de la amenaza a la seguridad interna. ¿Continuidad o ruptura? (1963-1970)", Contemporánea, año 3, vol. 3, 2012, pp. 149-166

Esteban Pontoriero. "Estado de excepción y contrainsurgencia: el plan CONINTES y la militarización de la seguridad interna en la Argentina (1958-1962), Contenciosa, año III, $n^{\circ} 4$, 2015, pp. 1-16,

Esteban Pontoriero. La seguridad interna como 'teatro de guerra': estado de excepción y contrainsurgencia en Argentina (1955-1976). Tesis de Doctorado, Buenos Aires, Universidad Nacional de San Martín, 2017.

Robert Potash. The Army and Politics in Argentina, 1928-1945: Yrigoyen to Perón. Stanford, Stanford University Press, 1969.

Hernán Ramírez. Corporaciones en el poder. Institutos y acción política en Brasil y Argentina. IPÊS, FIEL y Fundación Mediterránea. Buenos Aires, Lenguaje claro Editora, 2007.

Mario Ranaletti. "Aux origines du terrorisme d'État en Argentine", Vingtième siècle. Revue d'histoire, n. 1, 2010, pp. 45-56

Mario Ranaletti. "Una aproximación a los fundamentos del terrorismo de estado en la Argentina: la recepción de la noción de" guerra revolucionaria" en el ámbito castrense local (1954-1962)", Anuario del Centro de Estudios Históricos" Prof. Carlos Segreti", v. 11, n. 11, Córdoba, 2011, pp. 261-278 


\section{La historia transnacional de las derechas argentinas en el siglo XX: ¿qué sabemos y qué podríamos saber?}

Marie-Monique Robin. Escadrons de la mort, l'école française. París: La Découverte. 2004.

David Rock, La Argentina autoritaria. Los nacionalistas, su historia y su influencia en la vida pública. Buenos Aires, Ariel, 1993

Laura Graciela Rodríguez. "Los católicos desarrollistas en Argentina. Educación y planeamiento en los años de 1960", Diálogos, v. 17, n.1, 2013, p. 155-184.

Laura Graciela Rodríguez. "Los hispanismos en Argentina: publicaciones, redes y circulación de ideas", Cahiers des Amériques Latines, n. 79, 2015, pp. 97-114.

Laura Graciela Rodríguez. "La 'subversión científica' en las universidades de Argentina e Hispanoamérica”, Nuevo Mundo Mundos Nuevos, París, 2016, pp. 11-25. URL: https://nuevomundo.revues.org/68862

Julieta Rostica. "Una agenda de investigación pendiente: la política exterior de la dictadura militar argentina hacia Guatemala (1976-1983)", sitio web de la Asociación para el Fomento de los Estudios Históricos en Centroamérica, 2013.

Julieta Rostica. "La Confederación Anticomunista Latinoamericana y las Fuerzas Armadas. Guatemala y los años setenta", ponencia presentada en el II Coloquio Pensar las derechas en América Latina en el siglo XX. Universidad Nacional de General Sarmiento, 2016.

Alain Rouquié. Pouvoir Militaire et Société Politique en République Argentine. París, Presses de la Fondation Nationale des Sciences Politiques. 1978.

Stephan Ruderer. "Cruzada contra el comunismo. Tradición, Familia y Propiedad (TFP) en Chile y Argentina”, Sociedad y Religión, v. XXII, n. 38. 2012.

Mario Virgilio Santiago Jiménez. Juventudes católicas contra la 'amenaza comunista'. Estudio comparativo entre el Yunque de México y Tacuara de Argentina (1953-1964). Tesis de Doctorado, México D. F., Instituto de Investigaciones Dr. José María Luis Mora, 2016

Franco Savarino Roggero, y João Fábio Bertonha (coordinadores), El fascismo en Brasil y América Latina: ecos europeos y desarrollos autóctonos. México: INAH, Conaculta, 2013

Eugenia Scarzanella (coordinadora), Fascisti in Sud America. Florencia, Casa Editrice Le Lettere, 2005

Elena Scirica. "Visión religiosa y acción política. El caso de Ciudad Católica - Verbo en la Argentina de los años sesenta”. PROHAL Monográfico, n. 2, 2010, pp. 26- 56. 


\section{Ernesto Bohoslavsky}

Elena Scirica. "Educación y guerra contra-revolucionaria. Una propuesta de Ciudad Católica-Verbo”, Clio \& Asociados. La historia enseñada, 11, 2007, 119-140.

Martín Vicente. "La cuestión del liberalismo en Orden Cristiano: entre las posiciones antifascistas y la problemática identitaria (1941-1948)", Pasado Abierto, v. 1, n. 2, Mar del Plata, 2015

Michael Werner y Bénédicte Zimmerman. "Beyond comparison: histoire croisée and the challenge of reflexivity', History and theory, n. 45, 2006, pp. 30-50.

Loris Zanatta. Del Estado liberal a la nación católica. Iglesia y Ejército en los orígenes del peronismo. Buenos Aires, Universidad Nacional de Quilmes, 1996

Loris Zanatta. "De faro de la Hispanidad a centinela de Occidente. La España de Franco en América Latina entre la Segunda Guerra Mundial y la Guerra Fría”, Anuario IEHS, ${ }^{\circ} 23$, Tandil, 2008, pp. 47-73.

Loris Zanatta. La Internacional Justicialista. Auge y ocaso de los sueños imperiales de Perón. Buenos Aires, Sudamericana, 2013.

Gizele Zanotto. "A atuação do movimento católico Tradição, Família e Propriedade (TFP) no cenário político-cultural argentino (1967-1983)”, Revista Brasileira de História das Religiões, v. 20, 2014, p. 233-260.

Gizele Zanotto. "A Associação Tradição, Família e Propriedade no Brasil e sua expansão para a Argentina", en Cândido Moreira Rodrigues, Gizele Zanotto y Rodrigo Coppe Caldeira, (organizadores) Manifestações do Pensamento católico na América do Sul. São Paulo, Fonte Editorial, 2015, pp. 207-230.

Eduardo Zimmermann. Los liberales reformistas. La cuestión social en la Argentina 1890-1916. Buenos Aires, Sudamericana y Universidad San Andrés, 1995

Enrique Zuleta Álvarez. El nacionalismo argentino. Buenos Aires: La Bastilla. 1975.

Recibido: 04/09/2018

Evaluado: 01/10/2018

Versión Final: 26/12/2018 